\title{
Role of Arachidonic Acid and COX Inhibitors in the Regulation of Reproduction in Freshwater Crab Oziothelphusa senex senex
}

\author{
K Prameswari ${ }^{1}$, M Hemalatha ${ }^{1}$, B Kishori ${ }^{1 *}$ and P Sreenivasula Reddy ${ }^{2}$ \\ ${ }^{1}$ Department of Biotechnology, Sri Padmavati Mahila Visvavidyalayam (Women's University), Tirupati, Andhra Pradesh, India \\ ${ }^{2}$ Department of Zoology, Sri Venkateswara University, Tirupati, Andhra Pradesh, India
}

\begin{abstract}
Induced reproduction of cultured species helps to produce quantity and quality seed an important component for upright yield in crustacean aquaculture. The present study was aimed to investigate the role of arachidonic acid in the regulation of ovarian development in the freshwater crab, Oziothelphusa senex senex. Injection of AA significantly $(p<0.001)$ increased the ovarian index, oocyte diameter and ovarian vitellogenin levels. Injection of COX inhibitors such as indomethacin and aspirin alone, and in combination with AA resulted in significant $(p<0.001)$ reduction in ovarian index, oocyte diameter and ovarian vitellogenin levels in crabs. The results of the present study provide evidence that arachidonic acid and COX inhibitors involved in the regulation of female reproduction in the freshwater crab, Oziothelphusa senex senex.
\end{abstract}

Keywords: Arachidonic acid; COX inhibitors; Ovarian development; Crab

\section{Introduction}

Arachidonic acid (AA) is a polyunsaturated fatty acid and is the precursor for eicosanoids. It is metabolized by various enzymes and produces eicosanoids through the cyclooxygenase (COX) pathway and produce prostaglandin $\mathrm{G}_{2}\left(\mathrm{PGG}_{2}\right)$ and $\mathrm{H}_{2}\left(\mathrm{PGH}_{2}\right)$. Subsequently, prostaglandin synthase converts $\mathrm{PGH}_{2}$ to prostaglandins. Eicosanoids have an important role in the regulation of essential functions such as reproduction, haemostasis, growth, and the immune system in vertebrates. The occurrence of eicosanoids and their precursors have been identified in various invertebrates [1,2]. The presence of AA has been also identified in different crustaceans such as kuruma prawns, Penaeus japonicus and Marsupenaeus japonicus [3,4], green tiger prawn Penaeus semisulcatus [5], shrimps Penaeus monodon [6,7], Litopenaeus vannamei [8] and Penaeus merguiensis [9]. Furthermore, the presence of prostaglandins $\mathrm{PGE}_{2}$ and $\mathrm{PGF}_{2 a}$ were reported in Procambarus paeninsulanus [10], Marsupenaeus japonicus [4] and Penaeus monodon [11], whereas, only $\mathrm{PGE}_{2}$ was reported in Carcinus maenas [12]. Along with $\mathrm{PGE}_{2}$ and $\mathrm{PGF}_{2 \alpha}, \mathrm{PGD}_{2}$ also has been identified in the rice field crab Oziothelphusa senex senex [13]. The presence of $\mathrm{PGE}_{2}$ has been detected in the muscle and hemolymph of shrimp Penaeus monodon [14].

Similar to vertebrates, eicosanoids may also regulate the different physiological functions in invertebrates [15]. The physiological role of prostaglandins in the regulation of female crustacean reproduction was reported in few studies. Involvement of PG in ovarian maturation was studied with penaeid prawn Metapenaeus affinis [16], $\mathrm{PGE}_{2}$ and $\mathrm{PGF}_{2 \mathrm{a}}$ in the regulation of vitellogenesis and the induction of ovulation were reported in Procambarus paeninsulanus [10]. In the same species, $\mathrm{PGE}_{2}$ administration induced significant elevation of cAMP in ovarian tissue [17]. Later, similar results were reported in the prawn Macrobrachium rosenbergii and in the crayfish Cherax quadricarinatus [18]. Synthesis of $\mathrm{PGE}_{2}, \mathrm{PGF}_{2 \alpha}$ and $\mathrm{PGD}_{2}$ reported from isolated ovarian tissue of Oziothelphusa senex senex [13]. This study also reported that injection of $\mathrm{PGE}_{2}$ and $\mathrm{PGF}_{2 \alpha}$ increased ovarian index and oocyte diameter in a dose-dependent manner and no changes were observed on ovarian growth with an injection of $\mathrm{PGD}_{2}$ in Oziothelphusa senex senex. Recently, the variation of PGE levels at different vitellogenesis stages were demonstrated in freshwater prawn, Macrobrachium rosenbergii and administration of $\mathrm{PGE}_{2}$ stimulated the ovarian maturation, increasing ovarian somatic index, oocyte proliferation and vitellogenin $(\mathrm{Vg})$ level in the hemolymph of prawn [19]. In contrast to these studies, it was reported that injection of $\mathrm{PGE}_{2} 0.1 \mu \mathrm{g} / \mathrm{g}$ body weight did not stimulate the ovarian maturation in Penaeus esculentus [20].

The non-steroidal anti-inflammatory drugs (NSAID) may inhibit the biosynthesis of prostaglandins. NSAIDs exhibits competitive inhibition with arachidonic acid the substrate of COX enzyme thereby affects PGs biosynthesis and their physiological functions [21]. The negative role of NSAIDs in the synthesis of PGs also reported in crustaceans. Longterm exposure of ibuprofen (IBU) a NSAID, induced a dose-dependent reduction of reproduction in Daphnia magna [22]. In another study, it was reported that ibuprofen primarily affecting oogenesis rather than embryogenesis in daphnids, by interrupting eicosanoid (prostaglandin) metabolism [23]. In contrast, IBU affected reproduction negatively in Daphnia magna and Moina macrocopa [24]. Recently, Alfaro Montoya [25] reported the significant induced ovarian maturation with IBU treatment to unilateral eyestalk ablated of female Litopaneus stylirostris, whereas it had no effect on sperm counts and spermatophore weights in male Litopenaeus species. Though there are sporadic reports on the biosynthesis of PGs and their functions in crustaceans, the direct role of AA and COX inhibitors on reproduction in crustaceans are fragmentary. In view of this, the present study was tested the effect of AA and COX inhibitors, indomethacin and aspirin in the regulation of ovarian maturation in freshwater rice field crab Oziothelphusa senex senex.

\section{Materials and Methods}

\section{Collection and maintenance of crabs}

Female rice field crabs with a body weight $30 \pm 5 \mathrm{~g}$ (intermolt,

*Corresponding author: Dr. B Kishori, Asst. Professor, Department of Biotechnology, Sri Padmavati Mahila Visvavidyalayam (Women's University), Tirupati-517 502 Andhra Pradesh, India, Tel: 0877228 4588; E-mail: kktinku@rediffmail.com

Received May 09, 2017; Accepted July 10, 2017; Published July 12, 2017

Citation: Prameswari K, Hemalatha M, Kishori B, Sreenivasula Reddy P (2017) Role of Arachidonic Acid and COX Inhibitors in the Regulation of Reproduction in Freshwater Crab Oziothelphusa senex senex. J Aquac Res Development 8: 490 doi: 10.4172/2155-9546.1000490

Copyright: @ 2017 Prameswari K, et al. This is an open-access article distributed under the terms of the Creative Commons Attribution License, which permits unrestricted use, distribution, and reproduction in any medium, provided the original author and source are credited. 
Citation: Prameswari K, Hemalatha M, Kishori B, Sreenivasula Reddy P (2017) Role of Arachidonic Acid and COX Inhibitors in the Regulation of Reproduction in Freshwater Crab Oziothelphusa senex senex. J Aquac Res Development 8: 490. doi: 10.4172/2155-9546.1000490

Page 2 of 5

stage C4), uninjured were collected from in and around the Tirupati in Andhra Pradesh, India. The crabs were acclimated to laboratory conditions (temperature: $25-28^{\circ} \mathrm{C}$; light/dark $12: 12 \mathrm{~h}$ ) for 3 days before being used for the experiments. Crabs were fed daily with sheep meat ad libitum.

\section{Chemicals}

Arachidonic Acid (AA) (99\% Pure), Indomethacin (IM) and Aspirin (Asp) purchased from the Cayman Chemical company (USA), were used as test chemicals.

\section{Experimental design}

Randomly 140 crabs were divided into seven groups and 20 crabs each. Group 1 served as control and the crabs were sacrificed on the first day of the experiment. Crabs in the group 2 served as concurrent control and was received injections of crustacean saline [26] through the arthrodial membrane of the coxa of the third pair of walking legs. Crabs in the group 3 received injections of $10 \mu \mathrm{g} / 10 \mu \mathrm{l}$ of ethanol AA. Crabs in the groups 4 and 5 injected with at a dose of $10 \mu \mathrm{g}$ in $10 \mu \mathrm{l}$ of ethanol indomethacin and aspirin respectively. Crabs in groups 6 and 7 injected with AA (as in group 3), IM and Asp (as in groups 4 and 5) on the $1^{\text {st }}, 7^{\text {th }}, 14^{\text {th }}$ and $21^{\text {st }}$ day and the crabs were sacrificed on day 30 . No deaths were recorded in the concurrent controls or in the experimental groups.

\section{Ovarian index}

The crabs were weighed and the ovarian tissues were dissected out, blotted with paper towels and weighed wet using electronic balance and the gonad index was determined by using the following formula.

\section{Ovarian index $=$ Wet mass of the ovary}

/Wet mass of the crab $\times 100$

\section{Oocyte diameter}

The diameters of twenty-five oocytes $(\mu \mathrm{m})$ were measured from each freshly isolated ovary, using an ocular micrometer under the compound microscope. The average diameter of 25 oocytes in each ovary was considered as oocyte diameter.

\section{Ovarian histology}

The excised and clean ovaries were fixed in aqueous Bouin's fluid. After $24 \mathrm{~h}$ of fixation, the ovaries were dehydrated through an alcohol series, cleared in xylene and then embedded in paraffin (melting point $\left.56-58^{\circ} \mathrm{C}\right)$. Serial sections $(5 \mu \mathrm{m})$ were made and stained with haematoxylin and counter stained with eosin. The sections were photographed using phase contrast microscope.

\section{Estimation of vitellogenin levels using ELISA}

Vitellogenin was isolated from crab ovaries [27] and estimated the Vg content by Enzyme Linked Immuno Sorbent Assay (ELISA). Wells were coated with $20 \mu \mathrm{l}$ of sample diluted in 1:10 ratio with coating buffer (carbonate buffer: 1.59 g sodium carbonate, 2.93 g sodium bicarbonate in $1000 \mathrm{ml}$ distilled water, diethyl dithio carbonate (DIECA) $56 \mathrm{mg}$ per $25 \mathrm{ml}$ buffer). Blank values were obtained from wells coated with buffer alone. The plate is covered with a lid and placed in a humid chamber at $37^{\circ} \mathrm{C}$ for $2 \mathrm{~h}$. After discarding the contents, the plate was washed five times with 0.1 M Phosphate Buffer Saline containing 0.05\% Tween-20, pH 7.2 (PBST). Then, $200 \mu$ lof diluted (1:1000) primary antibody (antibodies raised in rabbits against crab vitellogenin isolated from vitellogenic stage III ovary from crab) in $0.1 \mathrm{M}$ PBST with $2 \%$ polyvinyl pyrrolidine, $0.2 \%$ ovalbumin (PBST-PO) is added to each well. The plate is covered with a lid and placed in a humid chamber at $37^{\circ} \mathrm{C}$ for $2 \mathrm{~h}$. The plate was washed 5 times with PBST after discarding the contents. After that $200 \mu \mathrm{L}$ of horseradish peroxidase (HRP) conjugated anti IgG antibody (1:1000 dilution with PBST-PO; purchased from Genei, Bangalore) was added to each plate and kept in dark for $1 \mathrm{~h}$ at $37^{\circ} \mathrm{C}$. The plate was washed 5 times with PBST and $200 \mu \mathrm{L}$ tetra methyl benzidene (TMB in $0.015 \%$ hydrogen peroxide) was added to each well. The plate was kept in dark for $1 \mathrm{~h}$ at $37^{\circ} \mathrm{C}$. The reaction was stopped by adding $50 \mu \mathrm{L}$ of $1 \mathrm{M}$ phosphoric acid per well. Absorbance of each well was measured using an ELISA-plates reader (Bio-Rad Lab., Model 680) at $450 \mathrm{~nm}$. All standard and sample measurements were performed in duplicate.

\section{Statistical analysis}

The significance of differences between the means was determined by performing one-way ANOVA (Tukey: Compare all pairs of columns) were carried out using SPSS 16.0 version software. Statistical significance was considered at $\mathrm{p}<0.001$.

\section{Results}

The ovary of the initial controls is in immature stage with a mean ovarian index of $0.322 \pm 0.024$ and oocyte diameter of $26.65 \pm 0.78$. No change in the mean ovarian index $(0.327 \pm 0.021)$ and oocyte diameter $(27.01 \pm 0.63)$ were found in the concurrent control group (Table 1) and are similar to controls. Injection of AA significantly $(p<0.001)$ increased the mean ovarian index $(1.568 \pm 0.11)$ and oocyte diameter $(68.36 \pm 1.19)$ with a maturation stage III (vitellogenic stage III) compared to control crabs (Table 1). Injection of COX-1 inhibitors indomethacin (IM) and aspirin (Asp) significantly $(\mathrm{p}<0.001)$ decreased the mean ovarian index $(0.228 \pm 0.023$ and $0.231 \pm 0.014$ respectively) and mean oocyte diameter $(22.12 \pm 1.02$ and $23.98 \pm 1.06$ respectively) compared to control crabs (Table 1). Co-injection of AA with either indomethacin or aspirin is also significantly decreased the ovarian index $(0.226 \pm 0.021$ and $0.230 \pm 0.024$ respectively) and oocyte diameter $(22.06 \pm 1.01$ and $23.66 \pm 1.05$ respectively) when compared with controls (Table 1). The ovarian vitellogenin levels of the initial control crabs were $0.158 \pm 0.088$ and similar $(0.160 \pm 0.055)$ in concurrent controls. The injection of Arachidonic acid significantly $(\mathrm{p}<0.001)$ increased the ovarian vitellogenin $(0.251 \pm 0.008)$ whereas

\begin{tabular}{|c|c|c|c|}
\hline Groups & $\begin{array}{l}\text { Ovarian index } \\
(\mathrm{g} \%)\end{array}$ & $\begin{array}{l}\text { Oocyte diameter } \\
(\mu \mathrm{m})\end{array}$ & Color of the ovary \\
\hline Control & $0.322 \pm 0.024$ & $26.65 \pm 0.78$ & White \\
\hline Concurrent control & $\begin{array}{c}0.327^{\mathrm{NS}} \pm 0.021 \\
(1.55)\end{array}$ & $\begin{array}{c}27.01^{\mathrm{NS}} \pm 0.63 \\
(1.35)\end{array}$ & White \\
\hline $\begin{array}{l}\text { Arachidonic acid } \\
\text { (AA) }\end{array}$ & $\begin{array}{c}1.568^{*} \pm 0.11 \\
(386.95)\end{array}$ & $\begin{array}{c}68.36^{*} \pm 1.19 \\
(156.51)\end{array}$ & Dark brown \\
\hline Indomethacin (IM) & $\begin{array}{c}0.228^{*} \pm 0.023 \\
(-29.19)\end{array}$ & $\begin{array}{l}22.12^{*} \pm 1.02 \\
\quad(-16.69)\end{array}$ & White \\
\hline Aspirin (Asp) & $\begin{array}{c}0.231^{*} \pm 0.014 \\
(-28.26)\end{array}$ & $\begin{array}{c}23.98^{*} \pm 1.06 \\
(-10.01)\end{array}$ & White \\
\hline$A A+I M$ & $\begin{array}{c}0.226^{*} \pm 0.021 \\
(-29.81)\end{array}$ & $\begin{array}{c}22.06^{\star} \pm 1.01 \\
(-17.22)\end{array}$ & White \\
\hline$A A+A s p$ & $\begin{array}{c}0.230^{*} \pm 0.024 \\
(-28.57)\end{array}$ & $\begin{array}{c}23.66^{*} \pm 1.05 \\
(-11.21)\end{array}$ & White \\
\hline$p$ value & $<0.001$ & $<0.001$ & \\
\hline F value & 2319.7 & 5882.4 & \\
\hline \multicolumn{4}{|c|}{$\begin{array}{l}\text { Values are mean } \pm \text { S.D. of } 20 \text { individuals. } \\
\text { Values in parentheses are percent change from control. } \\
\text { Values with * are significantly different from controls; NS: Not Significant. }\end{array}$} \\
\hline
\end{tabular}

Table 1: Effect of arachidonic acid and COX-1 inhibitors, indomethacin and aspirin on ovarian in fresh water crab, Oziothelphusa senex senex. 
Citation: Prameswari K, Hemalatha M, Kishori B, Sreenivasula Reddy P (2017) Role of Arachidonic Acid and COX Inhibitors in the Regulation of Reproduction in Freshwater Crab Oziothelphusa senex senex. J Aquac Res Development 8: 490. doi: 10.4172/2155-9546.1000490

Page 3 of 5

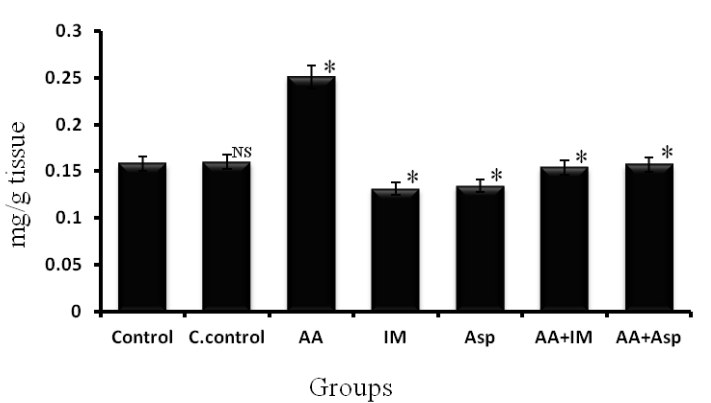

Bars with mean \pm S.D. of 20 individuals.

Bars with * are significantly changed from controls at $p<0.001 ;$ NS: Not significant.

Figure 1: Effect of arachidonic acid (AA), COX-1 inhibitors-indomethacin (IM) and aspirin (Asp) on ovarian vitellogenin levels in freshwater crab, Oziothelphusa senex senex.

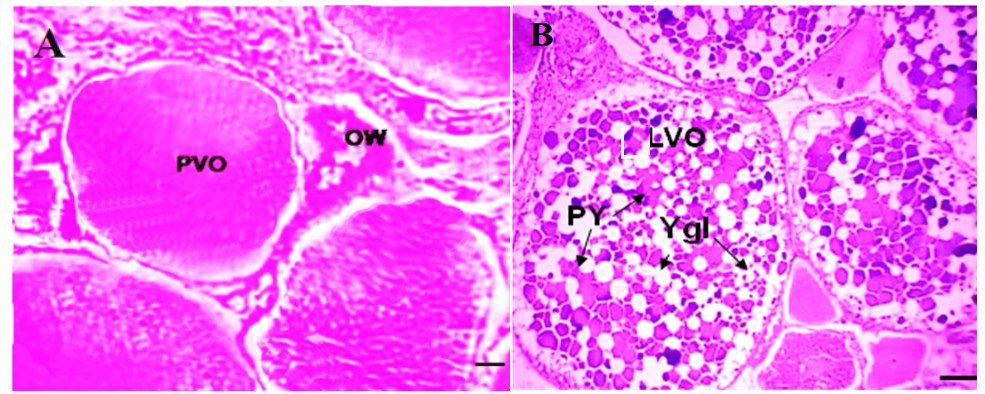

PVO: Pre-Vitellogenic Oocytes; OW: Thick Ovarian Wall; Ygl:Yolk Globules;

LVO: Late Vitellogenic Oocytes; PY: Protein Yolk;

Scale line $=10 \mu \mathrm{m}$.

Figure 2: (A) Histological appearance of the immature stage ovary (control) and (B) Vitellogenic stage III ovary (arachidonic acid injected) of the freshwater crab Oziothelphusa senex senex.

injection of indomethacin or aspirin significantly $(\mathrm{p}<0.001)$ decreased the ovarian vitellogenin $(0.131 \pm 0.005$ and $0.134 \pm 0.006$ respectively) (Figure 1). Co-injection of AA with either indomethacin or aspirin also significantly $(\mathrm{p}<0.001)$ decreased ovarian vitellogenin levels $(0.154$ \pm 0.004 and $0.157 \pm 0.002$ respectively) compared to controls (Figure 1 ).

At the end of the experiment, only the ovaries of AA injected crabs were in vitellogenic stage III (dark brown in colour). Histological sections of vitellogenic stage III contain a large accumulation of yolk globules occupies in the whole oocyte (Figure $2 \mathrm{~A}$ ) against immature ovary contain a thick ovarian wall with a centrally located germanium surrounded by no of oocytes (Figure 2B).

\section{Discussion}

In crustaceans, the ovaries undergo a series of developmental changes in color and increase in size during the reproductive cycle. Measurement of the ovarian index, oocyte diameter and histological changes of the ovary were the best indicators of measuring the female reproductive status in crustaceans [28,29]. Vitellogenesis is the synthesis and ovarian accumulation of yolk lipoprotein vitellogenin, a major nutritive component of embryo development after fertilization $[30,31]$. The vitellogenin concentration in various tissues correlates with the yolk accumulation in the oocyte [32,33]. The measurement of vitellogenin levels at different stages in the hemolymph and the ovary is used as additional criteria to determine the ovarian maturation in recent past [34].

In the present study, injection of AA resulted in a significant increase in the ovarian index, oocyte diameter, and ovarian vitellogenin levels with vitellogenic stage III ovary with enormous deposition of yolk histologically indicating the involvement of AA on ovarian maturation in crab. Several investigators hypothesized that AA regulates female reproductive development in crustaceans and presence of AA have been identified in several crustaceans [11]. Injection of arachidonic acid significantly induces maturation, in shrimp to Penaeus semisulcatus at a dose of $5 \mu \mathrm{g} / \mathrm{g}$ body weight and $10 \mu \mathrm{g} / \mathrm{g}$ body weights [35]. Earlier it was reported that arachidonic acid supplementation through diet significantly promotes reproductive performance in tank domesticated Penaeus monodon [36], in Daphnia magna [37] and improved gonad somatic index, hepatosomatic index, egg clutch weight and fecundity in prawn, Macrobrachium rosenbergii [38]. In several fishes, also Arachidonic acid supplementation increases reproduction [39-42].

$\mathrm{AA}$ is a precursor of $\mathrm{PGE}_{2}$ and $\mathrm{PGF}_{2}$, the role of $\mathrm{AA}$ in shrimp maturation has been suggested as a precursor for prostaglandins [43]. Further, this was supported by several studies in different crustaceans where PGs, stimulates ovarian maturation in freshwater prawn Metapenaeus affinis [16], in crayfish [17], in freshwater crab, Oziothelphusa senex senex [13], in the shrimp Penaeus monodon [11] and in the freshwater giant prawn Macrobrachium rosenbergii [19]. Recently, it was demonstrated that administration of $\mathrm{PGE}_{2}$ increases the vitellogenin levels in hemolymph of Macrobrachium rosenbergii [19]. Similar to earlier studies, in the present study, the regulation of reproduction in crab, Oziothelphusa senex senex by AA may connect to its role as a precursor to prostaglandins.

The prostanoid pathway converts polyunsaturated fatty acids into PGs by COX enzymes from substrate AA. The presence of COX pathway in crustaceans is also available $[18,44]$. To date, COX enzymes isolated, sequenced and characterized in two crustacean species, Gammarus 
Citation: Prameswari K, Hemalatha M, Kishori B, Sreenivasula Reddy P (2017) Role of Arachidonic Acid and COX Inhibitors in the Regulation of Reproduction in Freshwater Crab Oziothelphusa senex senex. J Aquac Res Development 8: 490. doi: 10.4172/2155-9546.1000490

Page 4 of 5

pulex and Caprella mutica [45]. COX has also been identified and sequenced in the shrimp Penaeus monodon [11]. Similar to mammals, NSAIDs affect the synthesis of PGs in invertebrates NSAIDs blocks the COX pathway $[18,45]$, thereby the physiological roles of PGs in the present study the injection of COX inhibitors, indomethacin and aspirin individually and co-administration with AA resulted in a significant decrease in ovarian index, oocyte diameter and ovarian vitellogenin levels. There are no direct studies available to support the present results, but previous studies supported the COX-inhibiting role of non-steroidal anti-inflammatory drugs in crustaceans $[21-25,19,46]$. The exposure to IBU reduces the reproductive performance in Daphina magna and Moina macrocopa [24]. Similarly, the treatment of IBU (0.01 $\mu \mathrm{g} / \mathrm{g}$ and $0.1 \mu \mathrm{g} / \mathrm{g}$ ) reduced ovarian maturation in unilaterally eyestalk ablated female and male Litopaneus species. It is also reported that 0.1 $\mu \mathrm{g} / \mathrm{g}$ of IBU significantly induced ovarian maturation in Litopenaeus stylirostris, but not in Litopenaeus vannamei whereas administration of IBU had no effect on sperm counts and spermatophore weights in Litopenaeus species [25]. COX inhibitor-indomethacin blocks the synthesis in Macrobrachium rosenbergii [47].

\section{Conclusion}

Administration of AA results in significant induction in ovarian development, whereas administration of COX inhibitors alone or in combination with AA inhibited the ovarian development in the crab. AA is deserved to act as a precursor induces synthesis of PGs. There by maturation takes place, on the other hand COX inhibitors blocks the PGs synthesis thus inhibits the maturation process. This study provides potential evidence that AA play a vital role in the regulation of reproduction. However, the regulatory mechanism of AA and COX inhibitors in crustaceans is yet to be known. Further emphasis is required to know the mechanistic action of arachidonic acid and PGs in ovarian development.

\section{References}

1. Stanley D, Howard RW (1998) The biology of prostaglandins and related eicosanoids in invertebrates: Cellular, organismal and ecological actions. American Zoologist 38: 369-381.

2. Rowley AF, Vogan CL, Taylor GW, Clare AS (2005) Prostaglandins in noninsectan invertebrates: Recent insights and unsolved problems. Journal of experimental biology 208: 3-14

3. Muriana FJ, Gutierrez V, Blaya JA, Bolufer J (1995) Phospholipid fatty acid composition of hepatopancreatic brush-border membrane vesicles from the prawn Penaeus japonicus. Biochimie 77: 190-193.

4. Tahara D, Yano I (2004) Maturation-related variations in prostaglandin and fatty acid content of ovary in the kuruma prawn Marsupenaeus japonicus. Comparative Biochemistry and Physiology Part A: Molecular \& Integrative Physiology 137: 631-637.

5. Ravid T, Tietz A, Khayat M, Boehm E, Michelis R (1999) Lipid accumulation in the ovaries of a marine shrimp Penaeus semisulcatus (de haan). Indian Journal of Experimental Biology 202: 1819-1829.

6. Meunpol O, Meejing P, Piyatiratitivorakul S (2005) Maturation diet based on fatty acid content for male Penaeus monodon (Fabricius) brood stock. Aquaculture Research 36: 1216-1225.

7. Huang JH, Jiang SG, Lin H, Zhou FL, Ye L (2008) Effects of dietary highly unsaturated fatty acids and astaxanthin on the fecundity and lipid content of pond-reared Penaeus monodon (Fabricius) broodstock. Aquaculture Research 39: 240251

8. Felix GM, Velazquez PM, Alvarez QJ (2009) Effect of various dietary levels of docosahexanoic and arachidonic acids and different $n-3 / n-6$ ratios on biological performance of Pacific white shrimp Litopenaeus vannamei raised in low salinity. Journal of the World Aquaculture Society 40: 194-206.

9. Chansela P, Goto-Inoue N, Zaima N, Hayasaka T, Sroyraya M (2012) Composition and localization of lipids in Penaeus merguiensis ovaries during the ovarian maturation cycle as revealed by imaging mass spectrometry. PLoS ONE 7: 1-12.

10. Spaziani EP, Hinsch GW, Edwards SC (1993) Changes in prostaglandin E2 and F2 alpha during vitellogenesis in the Florida crayfish Procambarus paeninsulanus. Journal of Comparative Physiology B 163: 541-545.

11. Wimuttisuk W, Tobwor P, Deenarn P, Danwisetkanjana K, Pinkaew D, et al (2013) Insights into the prostanoid pathway in the ovary development of the penaeid shrim Penaeus monodon. PLoS ONE 8: 115.

12. Hampson AJ, Rowley AF, Barrow SE, Steadman R (1992) Biosynthesis of eicosanoids by blood cells of the crab Carcinus maenas. Biochimica et Biophysica Acta 1124: 143-150.

13. Reddy PS, Reddy PR, Nagaraju GP (2004) The synthesis and effects of prostaglandins on the ovary of the crab Oziothelphusa senex senex. General and Comparative Endocrinology 135: 35-41.

14. Preechaphol R, Klinbunga S, Khamnamtong B, Menasveta $P$ (2010) Isolation and characterization of genes functionally involved in ovarian development of the giant tiger shrimp Penaeus monodon by suppression subtractive hybridization (SSH). Genetics and Molecular Biology 33: 676-685.

15. Stanley D (2006) Prostaglandins and other eicosanoids in insects: Biologica significance. Annual Review of Entomology 51: 25-44.

16. Sarojini R, Sambasiva RS, Jayalakshmi K, Nagabhushanam R (1989) Effect of $\mathrm{PGF}_{1}$ on ovarian maturation in a penaeid prawn Metapenaeus affinis. Journal of Zoological Research 2: 7-11.

17. Spaziani EP, Hinsch GW, Edwards SC (1995) The effect of prostaglandin E2 and prostaglandin F2 $\alpha$ on ovarian tissue in the Florida crayfish Procambarus paeninsulanus. Prostate 50: 189-200.

18. Silkovsky J, Chayoth R, Sagi A (1998) Comparative study of effects of prostaglandin $E_{2}$ on cAMP levels in gonads of the prawn Macrobrachium rosenbergii and the crayfish Cherax quadricarinatus. Journal of Crustacean Biology 18: 643-649.

19. Sumpownon C, Engsusophon A, Siangcham T, Sugiyama E, Soonklang $N$ et al. (2015) Variation of prostaglandin E2 concentrations in ovaries and its effects on ovarian maturation and oocyte proliferation in the giant freshwater prawn, Macrobrachium rosenbergii. General and Comparative Endocrinology 1:129-138.

20. Koskela RW, Greenwood JG, Rothlisberg PC (1992) The influence of prostaglandin $E_{2}$ and the steroid hormones, 17a-hydroxyprogesterone and $17 ß$-estradiol on molting and ovarian development in the tiger prawn Penaeus esculentus Haswell, 1879 Crustacea: Decapoda. Comparative Biochemistry and Physiology 101: 295-299.

21. Charlier C, Michaux C (2003) Dual inhibition of cyclooxygenase-2 (COX-2) and 5 -lipoxygenase (5-LOX) as a new strategy to provide safer non-steroidal antiinflammatory drugs. European Journal of Medicinal Chemistry 38: 645-659.

22. Heckmann LH, Callaghan A, Hooper HL, Connon R, Hutchinson TH, et al (2007) Chronic toxicity of ibuprofen to Daphnia magna: Effects on life history traits and population dynamics. Toxicology Letters 172: 137-145.

23. Heckmann LH, Sibly RM, Connon R, Hooper HL, Hutchinson TH, et al. (2008) Systems biology meets stress ecology: Linking molecular and organismal stress responses in Daphnia magna. Genome Biology 9: R40 1-15.

24. Han S, Choi K, Kim J, Ji K, Kim S, et al. (2010) Endocrine disruption and consequences of chronic exposure to ibuprofen in Japanese medaka Oryzias latipes and freshwater cladocerans Daphnia magna and Moina macrocopa. Aquatic Toxicology 98: 256-264.

25. Alfaro MJ (2015) The effect of ibuprofen on female and male reproduction of the open thelyca marine shrimp, Litopenaeus. Aquaculture research 46: 105-116.

26. Van Harreveld A (1936) A physiological solution for freshwater crustaceans. Proceedings of the Society for Experimental Biology and Medicine 34: 428-432.

27. Tsukimura B (2001) Crustacean vitellogenesis: Its role in oocyte development American Zoologist 41: 465-476.

28. Pillai KK, Nair NB (1971) The annual reproductive cycle of Uca annulipes, Portunus pelagicus and Metapenaeus affinis (Decapoda: Crustacea) from the South West coast of India. Marine Biology 11: 152-166.

29. Charniaux-Cotton H, Payen G (1988) Endocrinology of selected invertebrate types: Crustacean Reproduction. Alan R Liss, New York. 
Citation: Prameswari K, Hemalatha M, Kishori B, Sreenivasula Reddy P (2017) Role of Arachidonic Acid and COX Inhibitors in the Regulation of Reproduction in Freshwater Crab Oziothelphusa senex senex. J Aquac Res Development 8: 490. doi: 10.4172/2155-9546.1000490

Page 5 of 5

30. Tseng DY, Chen YN, Kuo GH, Lo CF, Kuo CM (2001) Hepatopancreas is the extra-ovarian site of vitellogenin synthesis in the tiger shrimp, Penaeus monodon. Comparative Biochemistry and Physiology 129: 909-917.

31. Zapata V, Lopez GLS, Medesani D, Rodriguez EM (2003) Ovarian growth in the crab, Chasmagnathus granulata induced by hormones and neuroregulators throughout the year. In vivo and in vitro studies. Aquaculture 224: 339-353.

32. Quackenbush LS (1989) Yolk protein production in the marine shrimp $P$. vannamei. Journal of Crustacean Biology 9: 509-516.

33. Okamura T, Han CH, Suzuki Y, Aida K, Hanyu I (1992) Changes in hemolymph vitellogenin and ecdysteriod levels during the reproductive and nonreproductive molt cycles in the freshwater prawn Macrobrachium nipponense. Zoological Science 9: 37-45.

34. Tsukimura B, Bender JS, Linder CJ (2000) Development of an anti-vitellin ELISA for the assessment of reproduction in the ridgeback shrimp Sicyonia ingentis. Comparative Biochemistry Physiology 127: 215-224.

35. Maheswarudu G, Vineetha A (2013) Littoral Oligochaete Pontodrilus bermudensis Beddard: A potential source for Arachidonic acid that stimulates maturation in penaeid shrimp. The Journal of Veterinary Science. Photon 114: 290-300.

36. Coman GJ, Arnold SJ, Barclay M, Smith DM (2011) Effect of arachidonic acid supplementation on reproductive performance of tank domesticated Penaeus monodon. Aquaculture Nutrition 17:141-151.

37. Ginjupalli GK, Gerard PD, Baldwin WS (2015) Arachidonic acid enhances reproduction in Daphnia magna and mitigates changes in sex ratios induced by pyriproxyfen. Environmental Toxicology and Chemistry 34: 527-535.

38. Kangpanich C, Pratoomyot J, Siranonthana N, Senanan W (2016) Effects of arachidonic acid supplementation in maturation diet on female reproductive performance and larval quality of giant river prawn Macrobrachium rosenbergii. Peer J 4: e2735.

39. Bessonart M, Izquierdo MS, Salhi M, Hernandez-Cruz CM, Gonzalez MM, et al. (1999) Effect of dietary arachidonic acid levels on growth and fatty acid composition of gilthead sea bream Sparus aurata L. larvae. Aquaculture 179: 265-275.

40. Koven W, Barr Y, Lutzky S, Ben-Atia I, Weiss R, et al. (2001) The effect of dietary arachidonic acid $(20: 4 n$ 6) on growth, survival and resistance to handling stress in gilthead sea bream Sparus aurata larvae. Aquaculture 193: 107-122.

41. Estevez A, Kaneko T, Seikai T, Tagawa M, Tanaka M (2001) ACTH and MSH production in Japanese flounder Paralichthys olivaceus larvae fed arachidonic acid-enriched live prey. Aquaculture 192: 309-319.

42. Bell GJ, Sargent JR (2002) Nutrition Group, Arachidonic acid in aquaculture feeds: Current status and future opportunities. Institute of Aquaculture, University of Stirling, Stirling FK9 4LA, Scotland, UK.

43. Middleditch BS, Missler SR, Hines HB, Brown A, Ward DC, et al. (1980) Metabolic profiles of penaeid shrimp: Dietary lipids and ovarian maturation. Journal of Chromatography 135: 359-368.

44. Valmsen K, Jarving I, Boeglin WE, Varvas K, Koljak R, et al. (2001) The origin of 15R-prostaglandins in the Caribbean coral Plexaura homomalla: Molecular cloning and expression of a novel cyclooxygenase. Proceedings of the National Academy of Sciences. USA 98: 7700-7705.

45. Varvas K, Kurg R, Hansen K, Jarving R, Jarving I (2009) Direct evidence of the cyclooxygenase pathway of prostaglandin synthesis in arthropods: Genetic and biochemical characterization of two crustacean cyclooxygenases. Insect Biochemistry and Molecular Biology 39: 851-860.

46. Hayashi Y, Heckmann LH, Callaghan A, Sibly RM (2008) Reproduction recovery of the crustacean Daphni magna after chronic exposure to ibuprofen. Ecotoxicology 17: 246-251.

47. Sagi A, Silkovsky J, Berkovich SF, Chayoth R (1996) Prostaglandin E2 in Previtellogeic Ovaries of the Prawn Macrobrachium rosenbergii: Synthesis and Effect on the Level of cAMP. General and Comparative Endocrinology 100: 308-313. 